\title{
Технологическая готовность будущего учителя к индивидуализации обучения школьников средствами педагогического дизайна
}

\author{
Беленко Т.В., Исаев И.Ф. \\ Белгородский государственный национальный исследовательский университет, \\ Россия, 308015, г. Белгород, ул. Победы, 85 \\ E-mail: belenko_t@bsu.edu.ru, isaev@bsu.edu.ru
}

\begin{abstract}
Аннотация. Поиск эффективных технологий обучения, позволяющих подготовить специалиста, удовлетворяющего запросам общества, является одной из актуальных проблем современной педагогики. В этой связи возрастает роль средств педагогического дизайна в процессе формирования технологической готовности будущих учителей к индивидуализации обучения школьников, которая обладает общими свойствами готовности будущего учителя к педагогической деятельности, но ей свойственны особенности, дающие основание рассматривать ее как специфический вид профессиональной готовности педагога. В статье обсуждаются результаты экспериментальной работы по подготовке студентов к индивидуализации обучения школьников с использованием средств педагогического дизайна. Целью данной работы являлось подтверждение влияния средств педагогического дизайна и комфортной образовательной среды на технологическую готовность будущих учителей к индивидуализации обучения школьников.
\end{abstract}

Ключевые слова: педагогический дизайн, индивидуальный образовательный маршрут.

Для цитирования: Беленко Т.В., Исаев И.Ф. 2020. Технологическая готовность будущего учителя к индивидуализации обучения школьников средствами педагогического дизайна. Вопросы журналистики, педагогики, языкознания, 39 (2): 178-187. DOI 10.18413/2712-7451-2020-39-2-178-187

\section{Technological readiness of the future teacher to individualize the teaching of students by means of educational design}

\author{
Tatyana V. Belenko, Ilya F. Isaev \\ Belgorod National Research University, \\ 85 Pobeda St, Belgorod, 308015, Russia \\ E-mail: belenko_t@bsu.edu.ru, isaev@bsu.edu.ru
}

\begin{abstract}
Individualization of education taking into account the characteristics and educational needs of a particular student is currently one of the main paradigms of the modern education system in Russia. Emerging problems in the organization of individual training are directly related to the lack of readiness of graduates of pedagogical specialties to individualize training. The task of modern pedagogical science is to find an effective training technology that allows you to prepare a specialist who meets the needs of society. Readiness to implement individualization of training has the General properties of the future teacher's readiness for pedagogical activity, but is characterized by features that give reason to consider it as a specific type of professional readiness of the teacher. One type of such readiness is technological
\end{abstract}


readiness. The article discusses the results of experimental work on the formation of technological readiness of students to individualize school education using instructional design tools. The purpose of this work was to confirm the influence of instructional design tools and a comfortable educational environment on the technological readiness of future teachers to individualize school education.

Keywords: technological readiness, individual educational route.

For citation: Belenko T.V., Isaev I.F. 2020. Technological readiness of the future teacher to individualize the teaching of students by means of pedagogical design. Issues in Journalism, Education, Linguistics, 39 (2): 178-187 (in Russian). DOI 10.18413/2712-7451-2020-39-2-178-187

\section{Введение}

Индивидуальный подход в обучении школьников, построение индивидуального маршрута обучения является актуальной проблемой современного образовательного процесса. Реальные возможности каждого обучающегося и программные требования федеральных стандартов требуют от учителя использования инновационных подходов к организации учебного процесса на основе информационных технологий. Учитель решает задачи обучения школьника к построениюсвоего индивидуального маршрута в непрерывном образовательном процессе на любом этапе жизненного пути. Современный учитель должен быть готов «осуществлять обучение, воспитание и развитие с учетом социальных, возрастных, психофизических и индивидуальных особенностей, в том числе особых образовательных потребностей обучающихся〉 ${ }^{1}$. Таким образом, вуз как среда профессионального обучения должен готовить специалистов, учителей, готовых «разрабатывать и реализовывать индивидуальные образовательные маршруты, индивидуальные программы развития и индивидуально-ориентированные образовательные программы с учетом личностных и возрастных особенностей обучающихся» ${ }^{2}$.

Проблема современной педагогической науки - поиск эффективной технологии обучения, позволяющей подготовить специалиста, удовлетворяющего запросам общества. Активное развитие информационных и цифровых технологий, а также проникновение их во все сферы жизни человека, обуславливает необходимость погружения системы образования в новую информационную среду. Научить школьника жить и работать в этой, быстро меняющейся среде - важнейшая задача школы.

Изучая проблему готовности будущих учителей к профессиональной деятельности, мы выделили готовность к индивидуализации обучения школьников как ее структурный компонент. В современных педагогических исследованиях нельзя найти единого алгоритма формирования готовности будущих учителей к индивидуализации обучения школьников. Каждый ученый, рассматривающий данный вопрос, использует свои инструменты и средства. В своих работах педагоги, ученые [Русинова, 2000; Шевченко, 2000; Исаев, Ерошенкова, 2011; Десятирикова, 2015 и др.] обращают внимание на необходимость изменения профессиональной подготовки будущих учителей к индивидуализации обучения, психолого-педагогической подготовки к изучению школьников.

Рассматриваемую готовность можно представить как многомерное новообразование, тесно связывающее профессионально-педагогические знания, ценностно-

1 Федеральный государственный образовательный стандарт высшего образования по направлению подготовки 44.03.05 Педагогическое образование (с двумя профилями) (уровень бакалавриата). Дата утверждения приказом Министерства образования и науки Российской Федерации от 9 февраля 2016 г., № 91. URL:https://base.garant.ru/70535556/ (дата обращения: 10.02.2020).

2 Профессиональный стандарт. Педагог (педагогическая деятельность в дошкольном, начальном общем, основном общем, среднем общем образовании) (воспитатель, учитель) от 18 октября 2013 г. № 544н. URL: http://fgosvo.ru /fgosvo/92/91/4/94 (дата обращения: 10.02.2020) 
мотивационную сферу, деятельностно-технологические инструменты и оценочнокоррекционные механизмы. В соответствии с этим в составе готовности к индивидуализации обучения можно выделить мотивационную готовность, теоретическую готовность, технологическую готовность и оценочную готовность.

Изучение состояния проблемы формирования готовности будущих учителей к индивидуализации обучения школьников на этапе констатирующего эксперимента привело нас к выводу о недостаточном использовании возможностей средств педагогического дизайна относительно исследуемой проблемы. Педагогический дизайн - достаточно новая отрасль в современной российской педагогике. И как любое новое явление оно имеет разнообразное обоснование своей сущности, принципов и особенностей [Smith, Ragan, 2005; Walter et al., 2005; Краснянский, 2006; Martin, 2008; Клепикова, 2009; Грецова, 2016; Патаракин, 2017 и др.]. Несмотря на это, конечная цель и задачи педагогического дизайна остаются едиными - создание психологически комфортной и благоприятной среды обучения для каждого учащегося. К основным принципам педагогического дизайна можно отнести: индивидуализацию, визуализацию, системность, минимизацию, комфортность, интерактивность [Ковалев, 2007]. В сфере профессионального образования происходят масштабные изменения: переход к непрерывному образованию, новые требования профессиональных стандартов подготовки специалистов, интеграция в европейское и мировое сообщество. Локомотивом прогресса во всех сферах жизни человека становятся информационные цифровые технологии и их интенсивное развитие, которые, в свою очередь, можно отнести к средствам педагогического дизайна.

Таким образом, выбор средств педагогического дизайна для формирования готовности можно считать обоснованным с точки зрения развития современной педагогической науки и актуальным в мире цифровизации образования.

\section{Обсуждение результатов исследования}

В нашем исследовании педагогический дизайн включает в себя последовательность следующих этапов: создание учебных событий через разработку стратегии обучения, подготовку сценария обучения, управление учением в сформированной с помощью информационных и цифровых технологий учебной среде и построение эффективного образовательного процесса, а также постоянную оценку деятельности учителя и ученика. Цель студента, будущего учителя, научиться с помощью педагогического дизайна создавать индивидуальный образовательный маршрут школьника, состоящий из набора учебных событий. Учебное событие - это значимая ситуация для ученика, имеющая у него внутренний отклик, позволяющая включаться в работу на равных, становясь равноправным организатором и творцом. Кроме того, учебное событие позволяет инициировать образовательную активность учащихся, деятельностное включение в разные формы образовательной коммуникации, интерес к созданию и представлению продуктов учебной и образовательной деятельности, формирование ответственного отношения к себе, и своим образовательным результатам.

В данной статье рассматривается влияние на формирование технологической готовности будущих педагогов к индивидуализации обучения школьников таких средств педагогического дизайна, как информационно-образовательная среда, электронный образовательный ресурс, UX/UI-дизайн. Технологическая готовность - это овладение инструментами и средствами реализации индивидуального подхода в обучении и построения индивидуальных образовательных маршрутов (ИОМ). Умения, входящие в состав указанной готовности, позволяют не только создать индивидуальный маршрут обучения средствами педагогического дизайна, но и организовать процесс обучения по этому маршруту. С их помощью решается проблема интеграции информационных образовательных ресурсов в учебный процесс и координация действий участников процесса индивидуализации. Тех- 
нологическая готовность будущих учителей к индивидуализации обучения средствами педагогического дизайна представляет собой практическую готовность, позволяющую перевести теоретические знания о педагогическом дизайне и его средствах в конкретные действия - разработку сценария обучения, создание электронного ресурса, организацию индивидуального взаимодействия.

Формирование технологической готовности будущих учителей к индивидуализации обучения средствами педагогического дизайна осуществлялось в рамках изучения курса «Информационные технологии в образовании» по авторской рабочей программе. Число студентов, участвующих в формирующем эксперименте, составило 76 человек, включенных в образовательный процесс по освоению программы обучения. Было создано две экспериментальные группы по направлению «Педагогическое образование» (ЭГ 1 и ЭГ 2), которые определялись профилями направления подготовки: соответственно (профиль «Русский язык и литература» - 40 человек и профиль «История и обществознание» 36 человек).

Интересующая нас готовность формировалась в процессе создания электронных образовательных ресурсов, внедрения их в систему электронного обучения (СЭО) «Пегас» по профилю направления подготовки студентов, участвующих в эксперименте; проектирования и построения ИОМ школьника; организации интерактивного взаимодействия в рамках созданного электронного пособия.

В ходе изучения и практического освоения курса «Информационные технологии в образовании» студентами выполнялись следующие работы:

1) создание диагностических форм (элементы: Анкета, Опрос, Обратная связь) для осуществления анализа целевой аудитории, определения индивидуальных возможностей и потребностей каждого обучающегося;

2) создание и настройка учебного курса в СЭО «Пегас» с учетом выявленных индивидуальных особенностей (ресурсы: Книга, Папка, Пояснение, Страница, Файл, Гиперссылка и элементы: Глоссарий, Задание, Рабочая тетрадь, Игра, Видеоконференция, Лекция, Тест), создание учебных элементов курса, в том числе и индивидуальных;

3) организация индивидуального взаимодействия (элементы: Форум, Чam, Onpoc, Обратная связь, Обмен сообщениями);

4) создание и проведение вебинаров с помощью Big Blue Button;

5) настройка балльно-рейтинговой системы оценивания каждого школьника.

Все, создаваемые студентами экспериментальных групп, элементы и ресурсы являются объектами информационно-образовательной среды в СЭО «Пегас», которая была представлена индивидуально разработанным курсом (рис. 1).

Особенностью педагогического дизайна в этом случае является то, что разрабатывается не только структура будущего курса, но и продумывается и выстраивается маршрут его изучения, в том числе и индивидуальный. Для этого необходимо учитывать индивидуальные физиологические и психологические особенности и образовательные потребности каждого учащегося. При создании электронных образовательных ресурсов студентами учитывались основные законы UX/UI дизайна. UX-дизайн (User Experience) - дизайн пользовательского опыта, UI-дизайн (User Interface) - дизайн интерфейса. К основным постулатам UX/UI дизайна можно отнести ряд законов: закон Хика-Хаймана, закон Фиттса, закон Якоба-Нильсена, закон Прагнанца, закон Миллера, закон Паркинсона, закон Теслера и эффектов: эффект Эббингауза, эффект Ресторфф, эффект Зейгарник. 


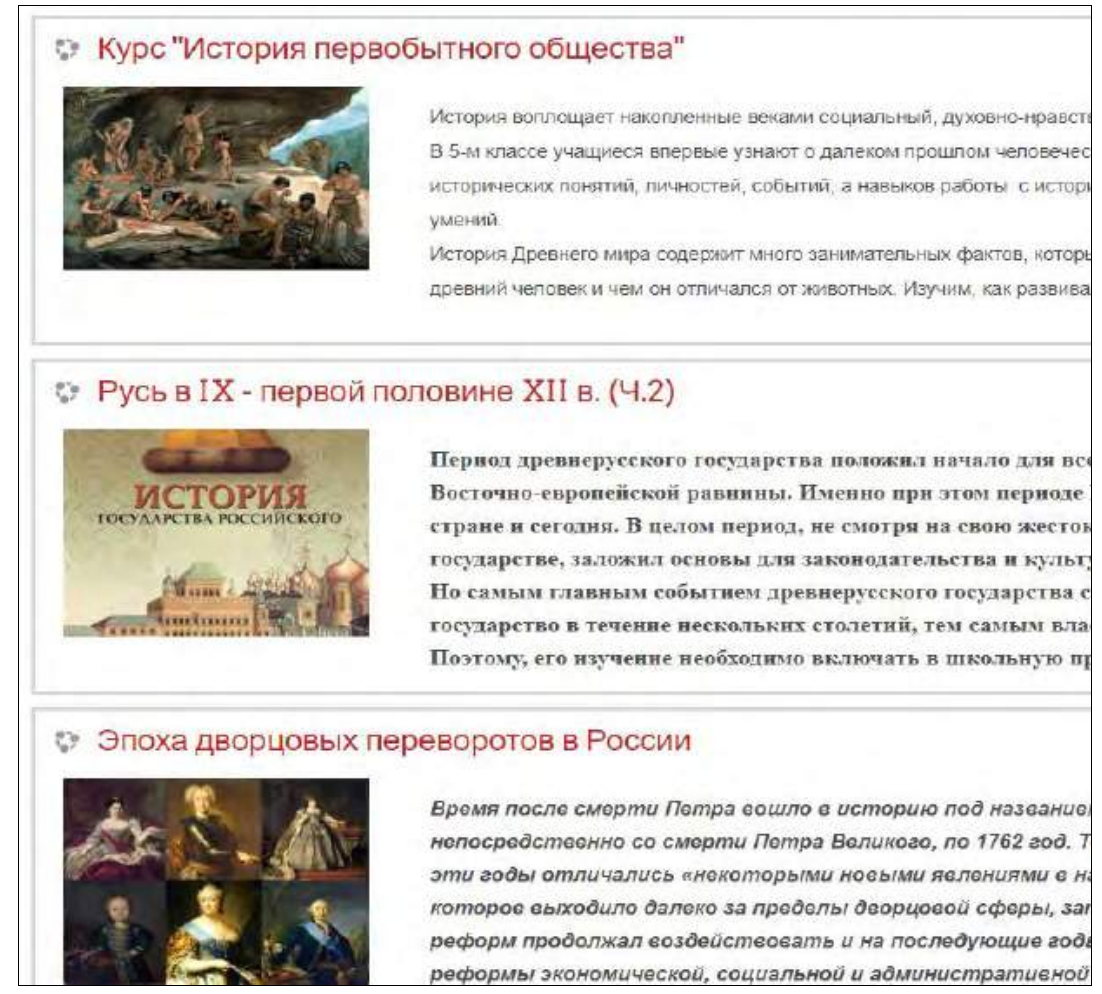

Рис.1. Курсы, созданные студентами в СЭО «Пегас»

Fig. 1. Courses created by students ate-learning system «Pegas»

Для изучения курса «Информационные технологии в образовании» была разработана комфортная среда обучения в СЭО «Пегас» НИУ «БелГУ» (рис. 2).
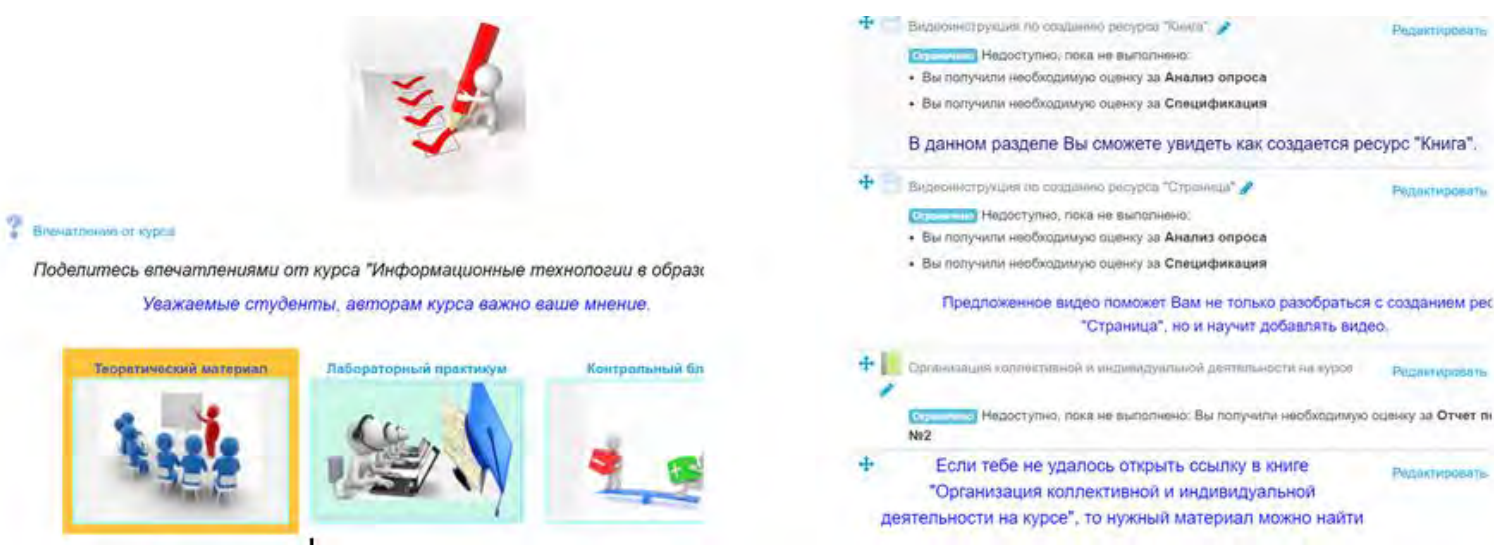

Рис. 2. Информационно-образовательная среда

Fig. 2. Informationandeducationalenvironment

СЭО «Пегас» построена на платформе системы управления образовательным контентом LMS Moodle. Moodle работает в операционных системах (OC) Unix, Linux, Windows, Mac OS X, Netware и любых других OC, поддерживающих язык разработки РНР и web-хостинг [Немцев и др., 2013]. Несомненными достоинствами выбранной среды являются визуализация процесса проектирования электронного учебного пособия; богатый набор всевозможных интерактивных ресурсов; возможность применения инструментария пользователями, не являющимися профессиональными программистами. Кроме того, в качестве альтернативных программных продуктов и сервисов необходимых для создания 
объектов, лежащих в основе индивидуальных маршрутов использовались такие средства, как Survey Monkey, Survio, Google, iSpring, Power Point, Windows Movie Maker, Biteable, Video Scribe и другие.

Удобство работы в созданной информационно-образовательной среде заключалось в том, что в ней был сосредоточен необходимый теоретический материал, требуемый набор практических заданий в форме лабораторного практикума, достаточный набор средств взаимодействия как с преподавателем, так и между обучающимися в формате онлайн или офлайн. Таким образом в указанной среде были организованы процесс обучения и процесс взаимодействия, при котором каждый студент мог работать по индивидуальному образовательному маршруту. Все указанные действия в дальнейшем позволили студентам создать индивидуальный образовательный маршрут для учащегося по изучению конкретной темы.

Для содержательного анализа и динамики сформированности технологической готовности будущих учителей к индивидуализации обучения школьников средствами педагогического дизайна были определены следующие показатели: умение разрабатывать сценарий учебного события средствами педагогического дизайна (У1), умение создавать электронные ресурсы средствами педагогического дизайна (У2), умение организовать индивидуальное взаимодействие (У3).

В ходе диагностики использовались разработанные электронные ресурсы (диагностические средства, объекты «Книга», «Папка», «Пояснение», «Страница», «Файл», «Гиперссылка», «Глоссарий», «Задание», «Рабочая тетрадь», «Игра», «Видеоконференция», «Лекция», «Тест»), созданные электронные курсы (состав элементов и ресурсов курса, правильность их создания, учет законов UX/UI дизайна), контрольное тестирование, созданные индивидуальные образовательные маршруты. Оценка показателей осуществлялась по стобалльной системе: низкий уровень - до 50 баллов, средний - от 50 до 80 баллов и высокий - больше 80 баллов. Каждый показатель был замерен до начала изучения курса «Информационные технологии в образовании» по авторской рабочей программе и по окончанию его изучения (табл.1).

Таблица 1

Table 1

Динамика сформированности технологической готовности Dynamicsoftechnologicalreadinessformation

\begin{tabular}{|c|l|c|c|c|c|}
\hline \multirow{3}{*}{ Показатели } & \multirow{2}{*}{ Уровень } & \multicolumn{2}{|c|}{ До изучения курса (\%) } & \multicolumn{2}{|c|}{ После изучения курса (\%) } \\
\cline { 3 - 6 } & & ЭГ 1 & ЭГ 2 & ЭГ 1 & ЭГ 2 \\
\hline \multirow{3}{*}{ У1 } & Низкий & 47,5 & 50 & 15 & 13,9 \\
\cline { 2 - 6 } & Средний & 40 & 41,7 & 50 & 50 \\
\cline { 2 - 6 } & Высокий & 12,5 & 8,3 & 35 & 36,1 \\
\hline \multirow{3}{*}{ У2 } & Низкий & 55 & 58,3 & 20 & 16,7 \\
\cline { 2 - 6 } & Средний & 42,5 & 41,7 & 55 & 25 \\
\cline { 2 - 6 } & Высокий & 2,5 & 0 & 25 & 11,1 \\
\hline \multirow{2}{*}{ У3 } & Низкий & 45 & 52,8 & 12,5 & 61,1 \\
\cline { 2 - 6 } & Средний & 52,5 & 41,7 & 57,5 & 27,8 \\
\cline { 2 - 6 } & Высокий & 2,5 & 5,5 & 30 & 25 \\
\hline
\end{tabular}


Для оценки значимости происходящих изменений в формируемой готовности использовался набор статистических методов, для определения достоверности совпадений и различий экспериментальных данных, измеренных в порядковой шкале (высокий, средний, низкий): критерий ц* - угловое преобразование Фишера; критерий однородности ч ${ }^{2}$ [Новиков, 2004]. Критическое значение для критерия ч ${ }^{2}$ для уровня значимости 0,05 в нашем случае равен 5,99, при этом достоверность различий до изучения курса и после его изучения составляет $95 \%$. Если сравнение результатов происходило по каждому из трех уровней конкретного показателя, то использовался критерий ц* - угловое преобразование Фишера. Критическое значение, позволяющее делать вывод о достоверности различий равно в нашем случае 2,31 .

Как мы видим, количество студентов, у которых сформировалось умение разрабатывать сценарий обучения (У1) на более высоком уровне значимо увеличилось после изучения курса (Цэмп $=4,709 \mathrm{p}<0,01$ и Цэмп $=3,799 \mathrm{p}<0,01)$. Этот результат является достоверным по угловому коэффициенту Фишера (рис. 3).

\section{ОСЬ ЗНАЧИМОСТИ:}

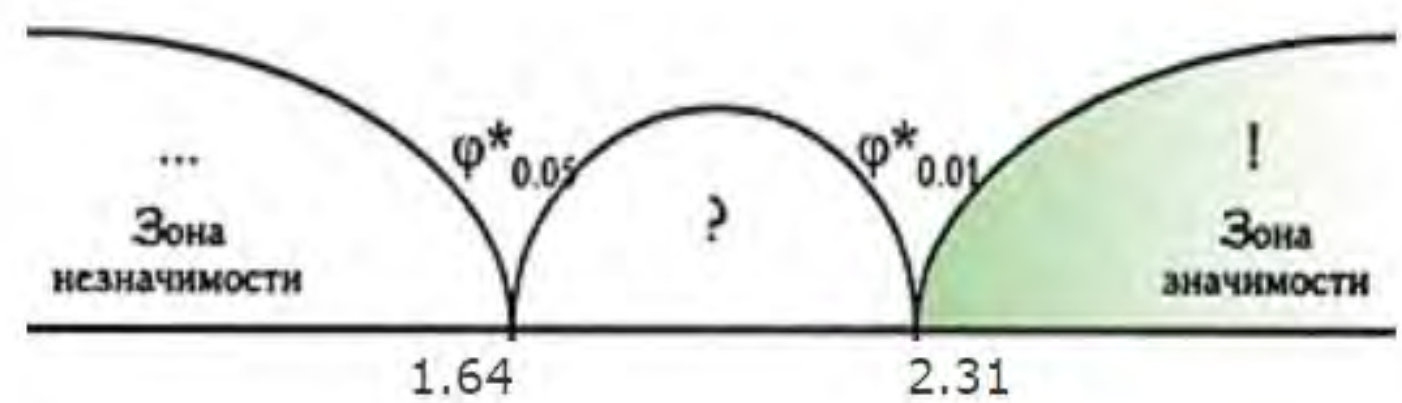

Рис. 3. Угловое преобразование Фишера

Fig. 3. Fisher angulartrans formation

Если рассмотреть показатель У1 по всем уровням, то ч ${ }^{2}{ }_{\text {эмп }}=11,468$ (ЭГ 1) и ч ${ }^{2}{ }_{\text {эмп }}=$ 13,87. Данные значения выше критического, следовательно, произошли значимые изменения у студентов экспериментальных групп ЭГ 1 и ЭГ 2. Это выражается в том, что студенты научились разрабатывать сценарий обучения через управление учением и построение развивающей среды для каждого конкретного обучающегося. Данные умения относятся к умениям высокого уровня.

Умение создавать качественные электронные учебные ресурсы (У2) средствами педагогического дизайна и внедрять их в индивидуальный маршрут обучения, также повысилось у студентов экспериментальных групп, и эти изменения являются значимыми $\left(ч^{2}{ }_{\text {эмп }}=14,54\right.$ и ч $\left.{ }^{2}{ }_{\text {эмп }}=14,94\right)$.

Достоверные различия в развитии показателя У3 (умение организовать индивидуальное взаимодействие) также произошли после изучения студентами экспериментальных групп курса «Информационные технологии в образовании».

Общие результаты изменения в показателях исследуемой готовности представлены в таблице 2.

Как мы видим, после изучения курса произошли достаточно значимые изменения: 60,5 \% студентов улучшили свои практические умения и навыки в реализации индивидуализации обучения школьников средствами педагогического дизайна $\left(\right.$ ч $\left.^{2}{ }_{\text {эмп }}=30,14\right)$, т.е. осуществили переход с низкого уровня на более высокий. 
Результаты сформированности технологической готовности

Resultsoftechnologicalreadinessformation

\begin{tabular}{|l|c|c|c|}
\hline \multicolumn{1}{|c|}{ Количество студентов } & Низкий уровень & Средний уровень & Высокий уровень \\
\hline до изучения курса, (\%) & 50,0 & 46,1 & 3,9 \\
\hline после изучения курса, (\%) & 14,5 & 56,6 & 28,9 \\
\hline
\end{tabular}

\section{Заключение}

Технологическая готовность современного педагога к индивидуализации обучения школьников включает в себя умения проектировать план и содержание каждого этапа индивидуального образовательного маршрута обучаемых, проектировать и создавать образовательную среду, в которой возможно реализовать индивидуальный образовательный маршрут обучающихся, умения обеспечивать сопровождение учебного процесса в образовательной среде, развивать коммуникативные навыки учащихся, осуществлять контроль познавательной деятельности, и может быть сформирована с помощью педагогического дизайна и его средств. Педагогический дизайн позволяет перейти от традиционных форм индивидуализации к проектированию их на информационных цифровых принципах. Учитель, владеющий средствами педагогического дизайна, может адекватно использовать соответствующие обучающие стратегии и методики для реализации индивидуализации обучения школьников, правильно подбирать среды, уместно использовать интерактивные компоненты и создавать из отдельных учебных модулей оптимальный маршрут обучения для каждого школьника.

Итак, можно сделать вывод, что освоение образовательной программы в рамках авторского курса «Информационные технологии в образовании» и обеспечение педагогически комфортной информационно-образовательной среды, созданной с помощью педагогического дизайна, организация обучения в ней - эффективные педагогические условия, позволяющие сформировать технологическую готовность будущих учителей к индивидуализации обучения средствами педагогического дизайна.

\section{Список литературы}

1. Грецова А.П. 2016. Развитие познавательных способностей старшеклассников средствами педагогического дизайна. Дис. ... канд. пед. наук. Саратов, 194 с.

2. Десятирикова Л.А. 2015. Формирование готовности будущих бакалавров педагогического образования к использованию компьютерных средств в профессиональной деятельности (на примере подготовки к обучению математике). Дис. канд. пед. наук. Тольятти, 180 с.

3. Исаев И.Ф., Ерошенкова Е.И. 2011. Профессионально-ценностная установка будущего специалиста: от сущности к технологии формирования. Сибирский педагогический журнал, 3: 44-53.

4. Клепикова А.Г. 2009. Подготовка будущего учителя к использованию педагогического дизайна в профессиональной деятельности. Автореф. дис. ... канд. пед. наук. Белгород, 24 с.

5. Ковалев Д.А. 2007 Педагогический дизайн: сущность и принципы. В кн.: Опыт использования сетевых информационных технологий и систем в образовательной и научнометодической работе. СПб., СПбГУ ИТМО: 133-137.

6. Краснянский М.Н., Радченко И.М. 2006 Основы педагогического дизайна и создания мультимедийных обучающих аудио / видео материалов. Тамбов, ТГТУ, 55 с. 
7. Немцев А.Н., Штифанов А.И., Беленко В.А., Загороднюк Р.А., Немцев С.Н., Гальцев O.В., Федосеев А.Э., 2013. Информационная система поддержки балльно-рейтинговой системы контроля знаний. Научные ведомости БелГУ. Серия История. Политология. Экономика. Информатика, 15 (158). Выпуск 27 (1): 217-222

8. Новиков Д.А., 2004. Статистические методы в педагогических исследованиях (типовые случаи). М., МЗ-Пресс, 67 с.

9. Патаракин Е.Д., 2017. Педагогический дизайн совместной сетевой деятельности субъектов образования. Автореф. дис. ... докт. пед. наук. Москва, 38 с.

10. Русинова М.М. 2000. Формирование основ готовности учителей к индивидуализации и дифференциации обучения в начальной школе. Дис. ... канд. пед. наук. Таганрог, 176 с.

11. Шевченко Т. М. 2000. Формирование готовности учителя к индивидуализации обучения средствами дистанционного образования в системе повышения квалификации Автореф. дис. ... канд. пед. наук. Ростов-на-Дону, 22 с.

12. DickW., CareyL., CareyJ.O. 2005. The Systematic Design of Instruction, Allyn\& Bacon: 1-12.

13. Martin F. 2008. Effects of Practice in a Linear and Non-linear Web-based Learning Environment. Educational Technology\&Society, 11(4): 81-93.

14. 1Smith P.L., Ragan T.J. 2005. Instructional Design. The University of Oklahoma. Hoboken, N.J.: Wiley \& Sons, 383 p.

\section{References}

1. Gretsova A. P. 2016. Razvitie poznavatel'nykh.sposobnostey.starsheklassnikov sredstvami pedagogicheskogo dizayna [Development of cognitive abilities of high school students by means of pedagogical design]. Dis. ... cand. ped. sciences, Saratov, 194 p.

2. Desyatirikova L.A. 2015. Formirovanie gotovnosti budushchikh bakalavrov pedagogicheskogo obrazovaniya $\mathrm{k}$ ispol'zovaniyu komp'yuternykh sredstv v professional'noy deyatel'nosti (na primere podgotovki $\mathrm{k}$ obucheniyu matematike) [Formation of readiness of future bachelors of pedagogical education to use computer tools in professional activities (on the example of preparation for teaching mathematics)]. Dis. ... cand. ped. sciences, Tol'yatti, $180 \mathrm{p}$.

3. Isaev I.F., Eroshenkova E.I. 2011. Vocational value orientations of the future expert: on the nature of the technology of forming. Siberian Pedagogical Journal, 3: 44-53 (in Russian)

4. Klepikova A.G. 2009. Podgotovka budushchego uchitelya k ispol'zovaniyu pedagogicheskogo dizayna v professional'noy deyatel'nosti [Preparing future teachers to use pedagogical design in their professional activities]. Abstract. dis. ... cand. ped. sciences, Belgorod, 24 p.

5. Kovalev D.A. 2007 Pedagogicheskiy dizayn: sushchnost' i printsipy [Pedagogical design: essence and principles]. In: Opyt ispol'zovaniya setevykh informatsionnykh tekhnologiy i sistem v obrazovatel'noy i nauchno-metodicheskoy rabote [The experience of using network information technologies and systems in educational and scientific-methodological work]. Sb. nauch. tr. SPb.: SPbGU ITMO: 133-137.

6. Krasnyanskiy M.N., Radchenko I.M. 2006 Osnovy pedagogicheskogo dizayna i sozdaniya mul'timediynykh obuchayushchikh audio/video materialov [Basics of pedagogical design and creation of multimedia teaching audio / video materials]. Tambov, Publ. TGTU, $55 \mathrm{p}$.

7. Nemtsev A.N., Shtifanov A.I., Belenko V.A., Zagorodnyuk R.A., Nemtsev S.N., Gal'tsev O.V., Fedoseev A.E., 2013.Information system to support point-rating control system of knowledge. Belgorod State University Scientific Bulletin History Political science Economics Information technologies, 15 (158). Issue27 (1): 217-222 (in Russian)

8. Novikov D.A., 2004 Statisticheskie metody v pedagogicheskikh issledovaniyakh (tipovye sluchai) [Statistical methods in pedagogical research (typical cases)]. M., Publ. MZ-Press, 67 p.

9. Patarakin E.D., 2017 Pedagogicheskiy dizayn sovmestnoy setevoy deyatel'nosti sub"ektov obrazovaniya [The pedagogical design of joint network activities of the subjects of education]. Abstract. dis... dokt. ped. sciences, Moskva, 38 p.

10. Rusinova M.M. 2000. Formirovanie osnov gotovnosti uchiteley k individualizatsii i differentsiatsii obucheniya v nachal'noy shkole [Formation of the foundations of teachers ' readiness for individualization and differentiation of education in primary schools]. Dis. ... cand. ped. sciences, Taganrog, 176 p. 
11. Shevchenko T. M. 2000. Formirovanie gotovnosti uchitelya $\mathrm{k}$ individualizatsii obucheniya sredstvami distantsionnogo obrazovaniya $\mathrm{v}$ sisteme povysheniya kvalifikatsii [Formation of teacher's readiness for individualization of training by means of distance education in the system of professional development]. Abstract. dis. ... cand. ped. sciences, Rostov-na-Donu, $22 \mathrm{p}$.

12. Dick W., Carey L., Carey J.O. 2005. The Systematic Design of Instruction, Allyn\& Bacon: 1-12.

13. Martin F. 2008. Effects of Practice in a Linear and Non-linear Web-based Learning Environment. Educational Technology\&Society, 11(4): 81-93.

14. Smith P.L., Ragan T.J. 2005. Instructional Design. The University of Oklahoma. Hoboken, N.J.: Wiley \& Sons, 383 p.

\section{ИНФОРМАЦИЯ ОБ АВТОРАХ}

Беленко Татьяна Владимировна, аспирант кафедры педагогики, начальник отдела маркетинга и организации приема Белгородского национального исследовательского университета, г. Белгород, Россия

Исаев Илья Федорович, доктор педагогических наук, профессор, профессор кафедры педагогики Белгородского национального исследовательского университета, г. Белгород, Россия

\section{INFORMATION ABOUT THE AUTHORS}

Tatyana V. Belenko, postgraduate student of the Department of pedagogy, head of marketing and reception Department, Belgorod national research University, Belgorod, Russia

Ilya I. Isaev, Doctor of pedagogical Sciences, Professor, Professor of the Department of pedagogy, Belgorod national research University, Belgorod, Russia 